\title{
BRIEF
}

\section{Design and Assessment of Pharmacy Student Delivered Preceptor Development}

\author{
Lisa M. Richter, PharmD, ${ }^{\mathrm{a}}$ Elizabeth Monson, PharmD, ${ }^{\mathrm{a}}$ Katelyn Bye, BS, ${ }^{\mathrm{a}}$ Jeanne E. Frenzel, PharmD, PhD ${ }^{\mathrm{a}, \mathrm{b}}$ \\ ${ }^{\text {a }}$ North Dakota State University, College of Health Professions, Fargo, North Dakota \\ ${ }^{\mathrm{b}}$ Editorial Board Member, American Journal of Pharmaceutical Education, Arlington, Virginia
}

Corresponding Author: Lisa M. Richter, North Dakota State University, College of Health Professions, PO Box 6050, Fargo, ND 58108. Tel: 701-231-5178. Email: Lisa.Richter.1@ndsu.edu

Submitted October 27, 2021; accepted January 18, 2022; ePublished January 2022

Objective. To design and assess the use of a pharmacy student delivered preceptor development (SDPD) program. Methods. An SDPD program was developed to ensure all preceptors received documented preceptor development. A menu of discussion topics and associated teaching sheets were created by the school's Office of Experiential Education (OEE). On each rotation, Advanced Pharmacy Practice Experience (APPE) students led discussions with their preceptors on a topic chosen by the preceptor and submitted documentation of the education. Preceptors answered a survey related to the amount of information and time required of the SDPD program, their preference for different formats of preceptor development, one important thing learned through the SDPD program, and future development topics of interest. Students were interviewed regarding their perceptions and use of the SDPD program.

Results. A novel SDPD program resulted in documentation of preceptor development for all APPE rotations. Seventynine preceptors (31\% response rate) participated in the survey. Preceptors agreed they were able to customize their preceptor development $(\mathrm{M}=3.7, \mathrm{SD}=0.84)$, incorporate what they learned into practice $(\mathrm{M}=3.7, \mathrm{SD}=0.74)$, it was a convenient format $(\mathrm{M}=4.0, \mathrm{SD}=0.66)$, and the $\mathrm{SDPD}$ was valuable to prepare students to be future preceptors $(\mathrm{M}=4.2$, $\mathrm{SD}=0.64)$. Students reported the SDPD improved their confidence in communicating with a supervisor and prepared them for precepting.

Conclusion. An SDPD program improved documented preceptor development. The program allowed preceptors to customize development opportunities in a convenient format. It was perceived positively by preceptors who would recommend the SPDP model to other schools of pharmacy for preceptor development.

Keywords: preceptor development; pharmacist extenders; experiential education

\section{INTRODUCTION}

Preceptors are vital in fostering the maturation of students into skilled pharmacists, inevitably shaping the future of pharmacy practice. With experiential education encompassing $30 \%$ of pharmacist education, the development of preceptors is important to pharmacy programs. ${ }^{1,2}$ Preceptor education and development fall under Standard 20 of the Accreditation Council for Pharmacy Education (ACPE) 2016 Accreditation Standards. ${ }^{3}$ Recent literature described one school's preceptor development needs assessment. ${ }^{4}$ Preceptors reported wanting the ability to choose preceptor development topics and wanting frequent sessions delivered via various formats including live at the practice location. ${ }^{4}$ Despite the importance of preceptor development, the best delivery method for preceptor development has yet to be identified. ${ }^{5,6}$

There are many challenges associated with preceptor development including time constraints, travel for in-person education, cost, lack of interest, and varied topic needs by preceptors. ${ }^{5}$ Pharmacy schools also experience barriers with assessing compliance of continuing professional development and limited resources needed to create variation in type of education and delivery format offered. ${ }^{2,7}$ These challenges prompted the school's Office of Experiential Education (OEE) to explore the implementation of student delivered preceptor development (SDPD) and its potential benefits for students, preceptors, and pharmacy programs.

The SDPD training was created at NDSU in response to a lack of documented preceptor development on all active preceptors which was a finding from a self-study survey used by the school of pharmacy (SOP) to prepare for an ACPE accreditation. NDSU uses volunteer preceptors, and the state of North Dakota does not require a Board of Pharmacy issued preceptor license. Preceptors received information about development opportunities, but participation was difficult to track. Many preceptors also precept for other SOPs or residency programs where they complete preceptor development that may be unaccounted for in the NDSU system. 
Rather than develop a robust documentation system requiring preceptors to input information, NDSU faculty developed and piloted an SDPD training focused on the Pharmacists' Patient Care Process (PPCP). ${ }^{8}$ A one-page document describing the PPCP was developed by the OEE. The program was introduced to all APPE students in the fall of 2019. Students were instructed to complete one PPCP training as part of the SDPD program per rotation. APPE students delivered PPCP focused training to preceptors for three 5-week rotations during the 2019-2020 year. In the spring of 2020, the COVID-19 pandemic negatively impacted the ability for students to deliver education to preceptors in person and thus the SDPD became optional.

This study aims to describe and assess a novel SDPD program delivered in 2020-2021. The primary objective of the SDPD program was to ensure that all preceptors received customized, documented training during each APPE rotation they facilitated. This objective needed to be achieved without additional financial resources from the school and with minimal impact on voluntary preceptor workload. A secondary objective was to increase student exposure to precepting topics for future precepting opportunities.

\section{METHODS}

The NDSU OEE consists of 2.05 faculty full-time equivalents (FTE) and 2.0 staff FTE dedicated to experiential education for an average 85 students per program year. Preceptor development delivered from the OEE has been previously described. ${ }^{9}$ APPE students were required to complete 8 of 9 available 5 -week block rotations including ACPE required rotations plus rural pharmacy practice and three electives.

In 2020-2021, changes to the piloted SDPD program at NDSU, a single institution, included expanding the training from PPCP training only to a menu of options which allowed preceptors to customize their learning. Twelve additional, one-page, trainings were created by the OEE with the help of academic APPE students. ${ }^{10}$ Topics were based on the ACPE Guidance for Standards 2016 preceptor preparation including: guidance regarding student's prior didactic experience and assessment/grading systems. Other topics were identified by the OEE based on frequent preceptor questions including how to view student evaluations of a preceptor, how to challenge the all-star student, the inclement weather policy or by preceptor request with examples including layered learning and student and preceptor wellbeing. ${ }^{11}$ Trainings can be modified to meet the needs of other institutions and are available upon request.

The SDPD was listed as a required activity in APPE syllabi. Student training included a short recording describing the SDPD training and a written overview of training details and deadlines. APPE students were instructed to read the training content created by the OEE, explore additional resources if applicable (included in 7 of 12 trainings) and lead a no more than 10-15-minute discussion with their preceptor about the topic at a convenient time during the rotation. An assessment of learning was built into each training by the OEE. Students could repeat topics from one rotation to the next. Contact information from the OEE was provided if there were any questions. A report was run in the rotation management system (RMS) after each rotation by the OEE and follow up via email occurred if no SDPD training was uploaded by the student.

The preceptor responsibilities included choosing a topic from the list, working with the student to identify a convenient time for the discussion, completing the multiple-choice or open-ended assessment question and signing the form which the student would upload in the RMS. Information about the training was communicated to preceptors in a biannual newsletter, during site calls/visits and in an information sheet provided to students for preceptors.

After a full year of the SDPD program, in June of 2021, a survey was administered electronically via Qualtrics (Provo, UT) to all active NDSU preceptors. Demographic questions included number of NDSU students precepted during 2020-2021 and type of rotation/s precepted. Preceptors answered two multiple-choice questions related to the amount of information and time commitment required of the SDPD program and ranked their preference for seven different formats of preceptor development. Preceptors answered seven 5-point Likert scale ( $1=$ strongly disagree to 5=strongly agree) questions related to the SDPD. Short answer questions asked about the most important thing preceptors learned through SDPD and what topics preceptors would like to learn about through the program. Participants who completed the entire survey were eligible for a drawing for one $\$ 50$ gift card. Descriptive statistics were used to analyze the data.

In September of 2021 an email was sent to NDSU Doctor of Pharmacy Class of 2021 alumni asking for participation in a focus group to obtain feedback on the SDPD. The focus group was conducted via videoconference and qualitative analysis was used to evaluate responses. Responses were coded and reviewed to remove redundancies, then categorized into themes and sub-themes by two members of the research team. To ensure the trustworthiness of the research in the qualitative sequence, the researchers used two-researcher peer-review as a credibility strategy. The two researchers conducted the coding and theming analysis independently, then discussed to reach consensus. Participants who completed the focus group received a \$20 gift card. The study was deemed exempt by the NDSU Institutional Review Board. 


\section{RESULTS}

Approximately $6 \%$ of $2020-2021$ APPE preceptors were faculty $(n=17)$ and the remaining $94 \%$ were adjunct volunteer preceptors $(n=254)$. The majority of 2020-2021 APPE rotations $(n=520 ; 77 \%)$ had a 1:1 student to preceptor ratio with the remaining rotations $2: 1(\mathrm{n}=158)$. Of the $2: 1$ student to preceptor ratio rotations $63 \%(\mathrm{n}=100$ rotations) were precepted by faculty preceptors.

The SDPD training resulted in documentation of preceptor education for all completed NDSU 2020-2021 APPE rotations ( $n=678$ rotations). For each rotation the APPE preceptor of record or preceptor designee completed the SDPD ( $\mathrm{n}=271$ different individuals). Two pharmacists other than the NDSU registered preceptor completed the education and, when precepting in teams $(n=7)$, only one preceptor of the group completed an SDPD training. There were a total of nine APPE preceptors of record (3\%) who did not sign off on a training due to the previous statement, however, all APPE rotations had an individual supervising the student who completed the SDPD.

Preceptors or designees $(n=271)$ most commonly completed one training topic $(n=135 ; 49.8 \%)$. Due to some preceptors taking multiple students throughout the year other preceptors documented two unique trainings $(\mathrm{n}=61 ; 22.5 \%)$; three unique trainings $(\mathrm{n}=35 ; 12.9 \%)$; and up to eight different trainings $(\mathrm{n}=2 ; 0.7 \%)$. Students were only required to upload one training so preceptors may have completed additional SDPD, but there was no requirement to document additional training.

When reviewed by rotation type, acute care rotations $(n=86)$ were most likely to receive training related to the student use of a new electronic health record (EHR Go $\left.{ }^{\mathrm{TM}}\right)$ in the didactic curriculum $(\mathrm{n}=12 ; 14.0 \%)$, ambulatory care rotations $(n=92)$ were most likely to receive training on the inclement weather policy $(n=19 ; 20.7 \%)$, institutional rotations $(n=96)$ were most likely to receive training related to guidance regarding student's prior didactic knowledge of aseptic technique $(n=17 ; 17.7 \%)$, and community rotations $(n=113)$ were most likely to receive training related to ideas to challenge the all-star student $(\mathrm{n}=22 ; 19.47 \%)$. The most frequent training completed included challenging the all-star student $(\mathrm{n}=98 ; 14.45 \%)$ and the inclement weather policy $(\mathrm{n}=90 ; 13.27 \%)$ (Table 1). Self-assessment questions were completed in $70.5 \%(\mathrm{n}=478)$ of completed training.

Seventy-nine of 255 currently active APPE preceptors (31\% response rate) completed a survey in June of 2021 to capture their perceptions and investment in the SDPD. Preceptors most frequently had two APPE students during the academic year $(\mathrm{n}=21 ; 27 \%)$ and were commonly associated with an advanced community rotation $(\mathrm{n}=22 ; 20 \%)$ or institutional rotation $(\mathrm{n}=16 ; 15 \%)$. Preceptors most frequently reported spending 5-10 minutes per training $(\mathrm{n}=38 ; 49 \%)$ with the vast majority expressing the training provided the right amount of information $(n=70 ; 89 \%)$. Most preceptors surveyed $(n=51,65 \%)$ agreed or strongly agreed that the SDPD allowed them to customize their training based on their individual needs and they were able to incorporate what they learned in the SDPD into their practice/precepting $(\mathrm{n}=54$; 68\%) (Table 2).

Preceptors rated the SDPD as their most preferred (most preferred $=1$; least preferred $=7$ ) preceptor development opportunity ( $\mathrm{M}=2.8 ; \mathrm{SD}=1.8)$ over electronic newsletters $(\mathrm{M}=3.03 ; \mathrm{SD}=1.99)$, recorded webinars (both NDSU specific $(\mathrm{M}=3.42 ; \mathrm{SD}=1.63)$ and general precepting $(\mathrm{M}=3.66 ; \mathrm{SD}=1.89)$, short recorded PowerPoints $(\mathrm{M}=4.43 ; \mathrm{SD}=1.56)$, live inperson $(\mathrm{M}=5.29 ; \mathrm{SD}=1.65)$ or live teleconference training $(\mathrm{M}=5.32 ; \mathrm{SD}=1.76)$. Preceptors commented that rotation customization $(n=14)$ or policies $(n=12)$ were the most important things learned and going forward they would like more SDPD on curriculum $(n=12)$ and clinical $(n=6)$ updates.

Eighty-six students participated in the SDPD program. Students completed anywhere from eight unique trainings $(\mathrm{n}=8 ; 9.3 \%)$ down to two unique trainings $(\mathrm{n}=3,3.5 \%)$ with five unique trainings as most common $(\mathrm{n}=22 ; 25.6 \%)$.

The focus group included six (7\%) individuals who participated in the 2020-2021 SDPD and was facilitated three months after graduation. The alumni reported the assignment instructions were unclear; however, they believed the SDPD helped them grow in confidence and prepared them for future precepting roles. In addition, they appreciated that the assignment was not time consuming, but felt they would learn more if the assignment options were broadened or they were able to choose the teaching topic. Lastly, they expressed concern about preceptors being unengaged in the process and perceived that non-alumni preceptors found the teaching more helpful than alumni preceptors.

\section{DISCUSSION}

The SDPD program was used to verify that for all APPE rotations a preceptor or preceptor designee received customized, documented training without additional financial resources from the school and with minimal impact on voluntary preceptor workload. The most requested training by preceptors included challenging high-performing students, the inclement weather policy, how to provide effective feedback, and the PPCP. All 2020-2021 APPE rotations were supervised by an individual who received documented preceptor development, of their choice, at the time of precepting. 
Preceptors reported spending less than 10 minutes on each SDPD training, appreciated the ability to choose their training, and used what they learned in practice or precepting.

Results from a student focus group found that students who facilitated SDPD while on rotation felt the training provided a unique way to connect with their preceptor. They also reported developing confidence and skills in talking to a supervisor. Students also noted that instructions for providing SDPD could have been improved.

In a published paper focused on excellence in experiential education, Boyce et al. encouraged the use of students on experiential rotations as extenders of pharmacy practice. ${ }^{12}$ In examples provided by the authors, students have played valuable roles in identifying cost-savings strategies, providing services such as medication reconciliation, and facilitating different types of patient education. ${ }^{12}$ Similarly, this study used students to as extenders of the OEE by facilitating preceptor development through a no cost, low time commitment SDPD. Boyce et al. also highlighted topics that preceptors should have knowledge of including the school or college of pharmacy mission, goals, and values, program specific policies, and systems training for any databases required for use by the school or college. ${ }^{12}$ The authors also recommended that schools and colleges provide preceptors with opportunities for continuous professional development. ${ }^{12}$ This study provides an example of a preceptor development program that is easily reproducible and transferable for use by other OEEs.

There is much published literature regarding the use of peer teaching with students in the health sciences. However, there is limited literature published regarding the use of reverse peer teaching in which junior students teach senior students, faculty, or preceptors. In 2014, Wirth and colleagues conducted a study of an education model in which medical students educated medical residents using a short presentation on a surgical topic during morning rounds. An exam and perception questionnaire were used to evaluate the model. ${ }^{13}$ Researchers reported that medical students were able to teach residents with the same effectiveness as a chief resident, the residents felt their surgical knowledge grew as a result of the teachings, and there was significant improvement in examination scores. ${ }^{13}$ Similarly, Clarke and colleagues described how reverse mentoring may be valuable to the health sciences. The researchers define reverse mentoring as a brief, but specific and focused relationship and suggest that junior health professionals may be ideal candidates to mentor senior clinicians in the use of new technologies, current trends in the field, and how to navigate changes to workplace culture. ${ }^{14}$

There were several limitations to this study. The study was completed at one institution during a pandemic. When not in a pandemic, front line preceptors may have more time to focus on preceptor development, but this program ensured all APPE students were supervised by an individual that received preceptor development. Even prior to the pandemic many preceptors had insufficient time, so SDPD may offer a convenient format for preceptors after the pandemic as well. The majority of preceptors were located in North Dakota and Minnesota however 9\% $(n=25)$ of preceptors who took APPE students during 2020-2021 were located out of area (Arizona, South Dakota, Texas, Hawaii, Indiana, Wisconsin, Montana, Colorado, Nebraska and Washington D.C.) providing some diversification to the findings. The focus group included only a small percentage (7\%) of the overall Doctor of Pharmacy class of 2021. Perceptions of the project may have been different if a larger number of individuals had participated in the focus group.

Some readers may feel that students may not be appropriate to deliver preceptor training, especially related to student issues such as remediation or feedback. However, students are routinely expected to educate pharmacy staff on new drugs or guidelines they may not have experience with without hesitation. Preceptors determined the topic and could avoid anything they were uncomfortable discussing with the student. These topics may also provide an opportunity for the preceptor and student to discuss expectations and consequences prior to the final evaluation. Additionally, many alumni go on to be preceptors and this gives them the opportunity for exposure to these topics prior to precepting themselves. SDPD should be used as part of a larger menu of preceptor development offerings to ensure all preceptors are receiving some form of preceptor development. Many trainings listed additional resources that pertain to the topic for further preceptor self-directed learning if desired.

Future direction for the SDPD included adding a limited menu of options as an Introductory Pharmacy Practice Experience (IPPE) assignment for 2021-2022. The training would be related to the recent SOP change in sequencing of community and institutional IPPE and the associated coursework that students completed prior to each type of IPPE rotation. This was deemed to be an appropriate topic for IPPE students to be qualified to deliver preceptor training on. Additionally, there are plans for adding new trainings to the APPE menu. Although students received verbal and written information about the assignment, based on feedback from the focus group additional measures will be added to ensure students have a thorough understanding of the importance of and expectations for the assignment.

Understanding student focused outcomes of the project should continue to be assessed but remain challenging due to the many variables involved. Further work to determine how to best evaluate student outcomes remains an important consideration in designing effective preceptor development. 


\section{CONCLUSION}

The SDPD program allowed APPE preceptors to receive customized, documented preceptor development. Both preceptors and students found benefit in the SDPD program, with preceptors appreciating the customization and applicability toward their precepting and students appreciating the connection with their preceptor and gained communication skills. The authors recommend the SPDP model and use of students on experiential rotations as extenders of pharmacy practice to augment existing preceptor development programs at other schools of pharmacy.

\section{ACKNOWLEDGEMENT}

The authors would like to acknowledge Kalley Pederson, PharmD for her contributions to data collection.

\section{REFERENCES}

1. Cox CD, Mulherin K, Walter S. National preceptor development program (PDP) prototype. The third of a 3-part series. Curr Pharm Teach Learn. 2018;10(3):298-306. doi:10.1016/j.cpt1.2017.12.003

2. O'Sullivan TA, Cox CD, Darbishire P, et al. the status and adequacy of preceptor orientation and development programs in us pharmacy schools. Am J Pharm Educ. 2020;84(2). doi:10.5688/ajpe7540

3. Standards2016FINAL.pdf. Accessed September 15, 2021. https://www.acpeaccredit.org/pdf/Standards2016FINAL.pdf

4. Williams CR, Wolcott MD, Minshew LM, Bentley A, Bell L. A qualitative preceptor development needs assessment to inform program design and effectiveness. Am J Pharm Educ. 2021;85(10). doi:10.5688/ajpe8450

5. Howard ML, Yuet WC, Isaacs AN. A review of development initiatives for pharmacy student and resident preceptors. Am J Pharm Educ. 2020;84(10). doi:10.5688/ajpe7991

6. Knott GJ, Mylrea MF, Glass BD. A scoping review of pharmacy preceptor training programs. Am J Pharm Educ. 2020;84(10). doi:10.5688/ajpe8039

7. Walter S, Mulherin K, Cox CD. A preceptor competency framework for pharmacists. Part 2 of a 3-part series. Curr Pharm Teach Learn. 2018;10(3):402-410. doi:10.1016/j.cptl.2017.11.018

8. PatientCareProcess-with-supporting-organizations.pdf. Accessed September 15, 2021. https://jcpp.net/wpcontent/uploads/2016/03/PatientCareProcess-with-supporting-organizations.pdf

9. Richter LM, Frenzel JE. Design and assessment of a preceptor development escape room. Am J Pharm Educ. Published online July 28, 2020. doi:10.5688/ajpe8073

10. Steenhoek RJ, Richter LM. An office of experiential education rotation for APPE students. Am J Pharm Educ. Published online April 23, 2021:8429. doi:10.5688/ajpe8429

11. GuidanceforStandards2016FINAL.pdf. Accessed November 6, 2019. https://www.acpeaccredit.org/pdf/GuidanceforStandards2016FINAL.pdf

12. Boyce EG, Harris CS, Bingham AL, et al. Striving for excellence in experiential education. JACCP J Am Coll Clin Pharm. 2020;3(3):678-691. doi:10.1002/jac5.1240

13. Wirth K, Malone B, Barrera K, Widmann WD, Turner C, Sanni A. Is there a place for medical students as teachers in the education of junior residents? Am J Surg. 2014;207(2):271-274. doi:10.1016/j.amjsurg.2013.11.001

14. Clarke AJ, Burgess A, van Diggele C, Mellis C. The role of reverse mentoring in medical education: current insights. Adv Med Educ Pract. 2019;10:693-701. doi:10.2147/AMEP.S179303 
Table 1. Preceptor Training Completed per Development Topic $(\mathrm{n}=678)$

\begin{tabular}{lc} 
Preceptor Education Topic & $\begin{array}{c}\text { Training Completed } \\
\text { Number (\%) }\end{array}$ \\
\hline How to Challenge the All-Star Student & $98(14.5)$ \\
Inclement Weather Policy & $90(13.3)$ \\
How to Provide Effective Feedback & $82(12.1)$ \\
Pharmacists' Patient Care Process & $76(11.2)$ \\
EHR Go ${ }^{\text {TM }}$ & $66(9.7)$ \\
Student and Preceptor Wellbeing & $58(8.6)$ \\
Layered Learning & $57(8.4)$ \\
How to View Student Evaluations in Rotation Management System & $50(7.4)$ \\
Student Didactic Experience with Aseptic Technique & $39(5.8)$ \\
APPE Remediation Policy & $30(4.4)$ \\
Student Didactic Experience with IPE \& Opportunities to Implement on Rotations & $26(3.8)$ \\
Preceptor's Choice & $6(0.9)$ \\
\hline APPE=advanced pharmacy practice experience & \\
EHR=electronic health record & \\
IPE=interprofessional education &
\end{tabular}

Table 2. Preceptor Responses to Perceptions of Student Delivered Preceptor Development ( $\mathrm{n}=79)$

\begin{tabular}{lc} 
& Mean (SD) \\
\hline SDPD allowed me to customize my preceptor development based on my individual needs & $3.7(0.84)$ \\
I was able to incorporate what I learned in SDPD into practice/precepting & $3.7(0.74)$ \\
SDPD offered a convenient format for preceptor development & $4.0(0.66)$ \\
I learned something new during SDPD & $3.7(0.91)$ \\
The SDPD met my preceptor development needs. & $3.5(0.90)$ \\
I would recommend the SDPD model to other Schools of Pharmacy for preceptor development & $3.7(0.92)$ \\
I think it is valuable for APPE students to discuss precepting topics such as in SDPD to better prepare students to be & $4.2(0.64)$ \\
future preceptors
\end{tabular}

$\mathrm{SDPD}=$ Student delivered preceptor development

$5=$ strongly agree; $1=$ strongly disagree 